\title{
Investigating the Potential of
}

\section{Phosphatidylcholine-Based Nano-Sized Carriers in Boosting the Oto-Topical Delivery of Caroverine: in vitro Characterization, Stability Assessment and ex vivo Transport Studies}

This article was published in the following Dove Press journal: International Journal of Nanomedicine

\author{
Amira Yousry Farrah' \\ Abdulaziz M Al-mahallawi iD ${ }^{2,3}$ \\ Emad B Basalious ${ }^{2}$ \\ Demiana I Nesseem (D) I \\ 'Department of Pharmaceutics, National \\ Organization for Drug Control and \\ Research, Cairo, Egypt; ${ }^{2}$ Department of \\ Pharmaceutics and Industrial Pharmacy, \\ Faculty of Pharmacy, Cairo University, Cairo, \\ Egypt; ${ }^{3}$ Department of Pharmaceutics, \\ Faculty of Pharmacy, October University for \\ Modern Sciences and Arts (MSA), Giza, \\ Egypt
}

Purpose: Drug delivery into the inner ear across the intact tympanic membrane (TM) has been a challenge in the treatment of inner ear disorders. In this study, nano-sized carriers were formulated for improving the non- invasive oto-topical delivery of caroverine for the treatment of tinnitus.

Methods: Caroverine was loaded into two types of phospholipid-containing systems, namely, nano elastic vesicles (EVs) and phosphatidylcholine-based liquid crystalline nanoparticles (PC-LCNPs). The prepared formulations were characterized for their drug loading, particle size, polydispersity index, zeta potential, morphological features by transmission electron microscopy (TEM), and physicochemical stability. In addition, comparative ex vivo transport study was carried out using rabbits' TM for both types of formulations.

Results: The findings show a significant superiority of PC-LCNPs over the EVs formulations in the drug payload ( $1 \%$ and $0.25 \%$, respectively), physical stability and the efficiency of permeation across rabbits' TM. The results showed a more than twofold increase in the cumulative drug flux values of PC-LCNPs $\left(699.58 \pm 100 \mu \mathrm{g} / \mathrm{cm}^{2}\right)$ compared to the EVs $(250$ $\pm 45 \mu \mathrm{g} / \mathrm{cm}^{2}$ ) across the TM.

Conclusion: The current study revealed the smart physicochemical properties of PC-LCNPs demonstrating the potential of this carrier as a new attractive candidate for improving the non-invasive oto-topical delivery of caroverine.

Keywords: caroverine, nanovesicles, liquid crystals, permeation, tympanic membrane

\section{Introduction}

Tinnitus is the perception of sound in the absence of real sound stimulation. For many people tinnitus is a ringing sound, while for others, it is whistling, buzzing, roaring, or shrieking. ${ }^{1}$ The sound may come from either one or both ears, from inside the head, or from a distance. It may be a constant sound or intermittent. Tinnitus is not a disease, but it is a symptom for presence of a certain disorder in the auditory system. ${ }^{2}$

In the mammalian cochlea, glutamate is the excitatory amino acid which mediates neurotransmission between inner hair cells and afferent neurons. ${ }^{3}$ In certain pathological conditions, such as brain ischemia and trauma, excessive amounts of
Correspondence: Emad B Basalious Department of Pharmaceutics and Industrial Pharmacy, Faculty of Pharmacy, Cairo University, Cairo I I562, Egypt Tel +2 01202000454

Email emad.basalious@pharma.cu.edu.eg
International Journal of Nanomedicine 2020:15 892I-8931

8921 
neurotransmitter glutamate is released which contributes to a pathological process described as excitotoxicity in the mammalian cochlea. This otoneurotoxicity model of glutamatergic action promises to cause the inner ear disease tinnitus with or without hearing loss. ${ }^{2}$

Caroverine,1-[2-(diethylamino)ethyl]-3-[(4-methoxyphenyl)methyl]-1,2-dihydroquinoxalin-2-one, has been shown to inhibit glutamate-receptors such as N-methylD-aspartate (NMDA) and $\alpha$-amino-3-hydroxyl-5-methyl4-isoxazole-propionate (AMPA) receptors, which in turn inhibit the disturbed induced activity of inner hair cell afferents that is hypothesized to happen in tinnitus. ${ }^{4}$ The efficacy of caroverine in the protection of human cochlea from excitotoxicity together with its intracochlear repair mechanisms stimulating effect allow it to be a promising therapy for the successful treatment of tinnitus. ${ }^{2}$

There are different strategies for inner ear drug delivery including systemic, intratympanic, and intracochlear delivery. ${ }^{5}$ The systemic drug administration for the treatment of inner ear diseases is restricted because of the blood-labyrinthine barrier and the limited blood supply to the inner ear. So inner ear diseases are not adequately treated by systemic drug administration. ${ }^{6}$ Local drug delivery methods as intratympanic and intracochlear administrations were developed to treat inner ear disorders efficiently. The intratympanic administration relies on drug diffusion through middle ear barriers and this technique is considered minimally invasive compared to intracochlear administration which offers direct access to the cochlea. ${ }^{7}$ However, in a "proof-of-concept" study, Ehrenberger tested the efficacy of oto-topical administration of caroverine in the treatment of tinnitus. ${ }^{2}$ In this study, a gauze soaked in $1 \%$ caroverine solution was inserted into the auditory ear canal of patients suffering from tinnitus. The obtained results suggest that the topical transtympanic administration of caroverine is a promising approach in the treatment of tinnitus.

Over the last decade, nanovesicular systems such as liposomes and transfersomes were utilized in the treatment of different otic disorders. ${ }^{8,9}$ However, several drawbacks have limited the industrial applications of these vesicular systems, for example, low drug pay loading, physical instability of the vesicular bilayer and sophisticated manufacturing technique of large batches.

The use of nano-carriers to improve the oto-topical delivery of the tinnitolytic agent, caroverine, has not yet been investigated. Therefore, the aim of this study was to enhance the non-invasive transtympanic flux of caroverine via loading into phosphatidylcholine based liquid crystalline nanoparticles (PC-LCNPs) as non-toxic, biocompatible nano system. In addition, caroverine-loaded phosphatidylcholine-based nano elastic vesicles (EVs) were prepared for comparative purposes. To verify the superiority of PC-LCNPs in transtympanic delivery, exvivo permeation studies of the PC-LCNPs were conducted in comparison with EVs and drug solution using rabbits' tympanic membrane (TM).

\section{Materials and Methods Materials}

Caroverine was kindly provided by Marcyrl Pharmaceutical Industries (Cairo, Egypt). L- $\alpha$-phosphatidylcholine (PC) from soya bean, glyceryl monooleate (GMO), Pluronic $\AA$ F-127 (PF-127), methanol (HPLC grade), and chloroform (HPLC grade) were purchased from Sigma-Aldrich Chemical Co. (St. Louis, Missouri, USA). Tween 80 (T80), ethanol (96\%), propylene glycol (PG), ammonium acetate, and glacial acetic acid were from El-Nasr Pharmaceutical Chemicals Co. (Cairo, Egypt). All other materials were of analytical grade.

\section{Methods}

\section{Preliminary Determination of the Optimum Concentration of Caroverine to Be Used for the Preparation of the Nano EVs}

The objective of this study was to determine the maximum drug concentration which could be used in the formulation and optimization of the nano EVs. Caroverine-loaded EVs were prepared with different drug concentrations $(0.25,0.5$, and $1 \% \mathrm{w} / \mathrm{v})$ to be evaluated with respect to their drug payload and solubilization efficiency. These formulations were prepared using thin film hydration technique (TFH), in which, accurate weight of caroverine $(25,50$ or $100 \mathrm{mg})$ was placed with $120 \mathrm{mg}$ $\mathrm{PC}$ and $30 \mathrm{mg}$ T80, into a round bottom flask and dissolved in an organic solvent mixture of chloroform and methanol $(1: 1 \mathrm{v} / \mathrm{v})$. These organic solvents were then evaporated by rotating the flask in a water bath at $60{ }^{\circ} \mathrm{C}$ under vacuum using rotary evaporator (Stuart, RE300, UK). After complete evaporation of the organic solvents, the dry thin film was hydrated with $10 \mathrm{~mL}$ of phosphate buffer saline (PBS, pH 7.4) containing $0.3 \%$ ascorbic acid (anti-oxidant) while rotating the flask under normal pressure for 30 minutes. Bath sonication (1 minute) was done for size reduction.

For determination of the drug payload, $1 \mathrm{~mL}$ of each formula was mixed with $50 \mathrm{~mL}$ methanol to dissolve the 
free drug and disrupt the drug loaded-vesicles. A chromatographic analysis was performed using a validated UPLC-UV method (ACQUITY UPLC H Class, Waters, USA). The validity of the UPLC-UV analytical method was established. The method was precise as the results of repeatability and ruggedness displayed \%RSD < $2 \%$. Also, there was a linearity between the peak area and the drug concentration (linearity equation was $y=17960 x+$ $11,000)$ and the regression coefficient $\left(\mathrm{R}^{2}\right)$ was 0.9994 . The mobile phase composed of ammonium acetate buffer $\mathrm{pH} 5$ and acetonitrile $(50: 50 \mathrm{v} / \mathrm{v})$. The flow rate was $0.2 \mathrm{~mL} / \mathrm{min}$ and the UV detector was set at $340 \mathrm{~nm}$. Aliquot of the alcoholic solution containing drug was then filtered using $0.22 \mu \mathrm{m}$ membrane filter and injected into a reversed phase (RP) C18 column (ACQUITY UPLC HSS, PS $1.8 \mu \mathrm{m}$, $50 \times 2.1 \mathrm{~mm}$, USA) maintained at $40{ }^{\circ} \mathrm{C}$. The drug payload was calculated as $(\%)$ of the theoretical drug content.

For the evaluation of the solubilization efficiency (SE), the three tested formulations were kept for $48 \mathrm{~h}$ in a refrigerator at $5^{\circ} \mathrm{C} \pm 3^{\circ} \mathrm{C}$ for accelerating the crystallization rate of the undissolved free drug. After that, sample from each formulation was filtered using $0.45 \mu \mathrm{m}$ membrane filter (to remove the precipitated drug). The drug payload was estimated in the filtrate as previously mentioned and SE was calculated using the following equation

$$
S E=\frac{\text { Drug payload after filteration }}{\text { Drug payload before filteration }} \times 100
$$

All the measurements were done in triplicate and the mean values \pm standard deviation (SD) were calculated. The drug concentration of the formula that showed SE> 95\% had been selected as the optimum one for preparation of EVs for subsequent optimization.

\section{Experimental Design for the Optimization of the EVs} Box-Behnken design utilizing Design-Expert 10.0.3 ${ }^{\circledR}$ (Stat-Ease, Inc., Minneapolis, MN) was employed to investigate the effect of the independent variables on the characteristics of the EVs (Table 1). Three numeric factors were evaluated, namely, total amount of lipid/surfactant mixture (PC/T80) (A), concentration (\%) of T80 in lipid/ surfactant mixture (B), and sonication time (C). Entrapment efficiency ( $\left.\mathrm{Y}_{1}: \mathrm{EE} \%\right)$, particle size ( $\left.\mathrm{Y}_{2}: \mathrm{PS}\right)$, polydispersity index $\left(\mathrm{Y}_{3}: \mathrm{PDI}\right)$, and zeta potential $\left(\mathrm{Y}_{4}: \mathrm{ZP}\right)$ were examined as responses for the design factors. The constraints used for the formulation optimization are also shown in Table 1. A total of 17 experiments were run;
Table I Box-Behnken Design Used for Optimization of Caroverine-Loaded EVs

\begin{tabular}{|l|l|l|l|}
\hline \multirow{2}{*}{ Factors (Independent Variables) } & \multicolumn{2}{|l|}{ Levels } \\
\cline { 2 - 4 } & $\begin{array}{l}\text { Low } \\
\mathbf{( - 1 )}\end{array}$ & $\begin{array}{l}\text { Medium } \\
(\mathbf{0})\end{array}$ & $\begin{array}{l}\text { High } \\
(+1)\end{array}$ \\
\hline $\begin{array}{l}\text { A: Total amount of (PC/T80) mixture } \\
(\mathrm{mg})\end{array}$ & 100 & 150 & 200 \\
$\begin{array}{l}\text { B: Concentration of T80 in (PC/T80) } \\
\text { mixture (\%) } \\
\text { C: Sonication time (min) }\end{array}$ & 10 & 20 & 30 \\
\hline Responses (Dependent Variables) & Desirability \\
\hline$Y_{1}:$ EE\% & Constraints & 2 \\
\hline$Y_{2}:$ PS $(\mathrm{nm})$ & $>60 \%$ \\
\hline$Y_{3}:$ PDI & $<750$ \\
\hline$Y_{4}:$ ZP $(\mathrm{mV})$ & $<0.5$ \\
\hline
\end{tabular}

twelve of them represent the mid-point of each edge of the multidimensional cube and the remaining five are the replicates of the cube's center point (Table 2). This allows the estimation of pure error which enables the calculation of the response of intermediate levels and consequently permits the estimation of the system performance at any experimental point within the studied range. ${ }^{10}$ Desirability was calculated for selection of the optimized formula which was subjected for further investigations.

\section{Characterization of Caroverine-Loaded EVs Drug Payload and EE \%}

Drug payload of the prepared caroverine-loaded elastic nano-vesicular dispersion was determined as previously mentioned. The EE \% was also determined by centrifuging $1 \mathrm{~mL}$ of the dispersion at $4{ }^{\circ} \mathrm{C}$ for an hour at $15,000 \mathrm{rpm}$ (Hermle, Z 326 k, Germany) and measuring the drug concentration in the residue after disruption by sonication with methanol. The $\mathrm{EE} \%$ was calculated using the following formula:

$$
E E \%=\frac{\text { Amount of caroverine entrapped }(\mathrm{mg})}{\text { Total amount of caroverine }(\mathrm{mg})} \times 100
$$

All the measurements were done in triplicate.

\section{Determination of PS, PDI, and ZP}

Average PS (z-average), PDI, and ZP of the prepared vesicles were determined by Zetasizer Nano ZS (Malvern Instruments, Malvern, UK) at $25^{\circ} \mathrm{C}$. The dispersion was 
Table 2 Experimental Runs, Independent Variables and Measured Responses of the Box-Behnken Experimental Design of the Caroverine-Loaded EVs

\begin{tabular}{|c|c|c|c|c|c|c|c|}
\hline \multirow[t]{2}{*}{ Formula } & \multirow[b]{2}{*}{$\begin{array}{l}\text { Total Amount of } \\
\text { Lipid/Surfactant } \\
\text { Mixture } \\
\text { (PC/T80) (mg) }\end{array}$} & \multicolumn{2}{|l|}{ Design Factors } & \multicolumn{4}{|c|}{ Design Responses } \\
\hline & & $\begin{array}{l}\text { Concentration of T80 in } \\
\text { Lipid/Surfactant Mixture } \\
\text { (\%) }\end{array}$ & $\begin{array}{l}\text { Sonication } \\
\text { Time } \\
(\mathrm{min})\end{array}$ & $\begin{array}{l}\text { YI: } \\
\text { (EE) } \\
\%\end{array}$ & $\begin{array}{l}\text { Y2: } \\
\text { (PS) } \\
\text { nm }\end{array}$ & $\begin{array}{l}\text { Y3: } \\
\text { (PDI) }\end{array}$ & $\begin{array}{l}\text { Y4: } \\
(Z P) \\
m V\end{array}$ \\
\hline I & 200.00 & 20.00 & 0.00 & 71.60 & 984.75 & 0.30 & -34.80 \\
\hline 2 & 150.00 & 10.00 & 2.00 & 75.80 & 777.65 & 0.24 & -35.20 \\
\hline 3 & 150.00 & 20.00 & 1.00 & 69.20 & 732.55 & 0.25 & -47.30 \\
\hline 4 & 150.00 & 20.00 & 1.00 & 74.78 & 720.90 & 0.21 & -39.80 \\
\hline 5 & 150.00 & 10.00 & 0.00 & 73.97 & 742.50 & 0.37 & -48.05 \\
\hline 6 & 100.00 & 20.00 & 2.00 & 68.08 & 541.45 & 0.60 & -43.80 \\
\hline 7 & 200.00 & 20.00 & 2.00 & 77.39 & 913.70 & 0.30 & -46.15 \\
\hline 8 & 150.00 & 20.00 & 1.00 & 68.36 & 740. 00 & 0.64 & -46.30 \\
\hline 9 & 200.00 & 10.00 & 1.00 & 75.70 & 812.35 & 0.22 & -52.30 \\
\hline 10 & 100.00 & 20.00 & 0.00 & 76.50 & 589.50 & 0.61 & -45.85 \\
\hline 11 & 150.00 & 30.00 & 0.00 & 66.90 & 633.60 & 0.25 & -42.35 \\
\hline 12 & 150.00 & 20.00 & 1.00 & 64.48 & 708.35 & 0.56 & -44.95 \\
\hline 13 & 200.00 & 30.00 & 1.00 & 79.50 & 728.70 & 0.15 & -42.70 \\
\hline 14 & 100.00 & 10.00 & 1.00 & 67.00 & 638. 00 & 0.59 & -52.85 \\
\hline 15 & 150.00 & 30.00 & 2.00 & 73.70 & 573.80 & 0.26 & -39.60 \\
\hline 16 & 100.00 & 30.00 & 1.00 & 69.00 & 556. 00 & 0.27 & -50.80 \\
\hline 17 & 150.00 & 20.00 & 1.00 & 89.40 & 824. 00 & 0.75 & -50.95 \\
\hline
\end{tabular}

diluted with deionized water at a ratio of $1: 99 \mathrm{v} / \mathrm{v}$ prior to measuring the PS and PDI; to ensure the uniform distribution of the vesicles in the dispersion. The ZP of the appropriately diluted samples (with deionized water) was measured by observing the electrophoretic mobility of charged vesicles in an electrical field in order to assess the physical stability of the dispersion. ${ }^{11}$ All the measurements were done in triplicate.

\section{Preparation of PC-LCNPs Containing High Caroverine Load}

PC-LCNPs were prepared using liquid precursor dilution technique, $^{12}$ in which, the non-aqueous (precursor) phase was prepared by mixing L- $\alpha$-phosphatidylcholine (PC) and glyceryl monooleate (GMO) with ethanol and propylene glycol (PG). T80 and Pluronic ${ }^{\circledR}$ F127 (PF-127) were added to the non-aqueous solution as a steric stabilizers that prevent the aggregation and agglomeration of the dispersion. The aqueous phase contained caroverine (1\% $\mathrm{w} / \mathrm{v}$ ), ascorbic acid, and acetic acid. Liquid crystalline phase was formed by dispersing the non aqueous precursor in the drug solution by hand shaking. Homogenization was then applied using the homogenizer (T 25 digital ULTRATURRAX $^{\circledR}$, IKA, Germany) for 5 minutes at $3000 \mathrm{rpm}$ for enhancing the liquid crystalline (LC) phase dispersibility and ensuring the homogenous distribution of the LCNPs. The final composition (w/v) of the prepared PC-LCNPs is 5\% GMO, 0.5\% PC, 35\% PG, 5\% ethanol, 0.3\% T80, $0.6 \% \mathrm{PF}-127,0.3 \%$ ascorbic acid, $0.6 \%$ acetic acid, and $55 \%$ distilled water.

\section{Characterization of Caroverine-Loaded PC-LCNPs}

The caroverine-loaded PC-LCNPs system was evaluated with respect to its visual appearance, drug payload, PS, PDI, and ZP, as previously mentioned.

\section{Comparative Physicochemical Stability Study of Caroverine-Loaded EVs and PC-LCNPs}

The optimized EVs and PC-LCNPs formulations were prepared and filled in type I transparent glass vials each of $10 \mathrm{~mL}$ for stability follow-up. The tested formulations were stored in a refrigerator at $5^{\circ} \mathrm{C} \pm 3^{\circ} \mathrm{C}$ and in a cabinet at $30^{\circ} \mathrm{C} \pm 2{ }^{\circ} \mathrm{C} / 65 \% \mathrm{RH} \pm 5 \% \mathrm{RH}$ (accelerated condition). The samples were kept for 3 months and evaluated for their drug payload, physical appearance, PS, PDI and ZP compared to the fresh ones at the end of the storage period. The difference in values between the fresh and stored samples was statistically analyzed using paired- $t$-test utilizing SPSS $17.0^{\circledR}$ software (SPSS Inc., Chicago, USA). 
Difference at $P \leq 0.05$ was considered significant. All measurements were performed in triplicate and the results were displayed as mean values $\pm \mathrm{SD}$.

\section{Morphology of Caroverine-Loaded EVs and PC-LCNPs Using Transmission Electron Microscopy} The optimized EVs and PC-LCNPs formulations were observed by transmission electron microscopy (TEM) operated at $80 \mathrm{kV}$ (model JEM-1230, JEOL, Tokyo, Japan). One drop of the diluted formula was adsorbed on a carbon-coated copper grid, negatively stained with $2 \%$ phosphotungstic acid, and then allowed to dry at room temperature prior to examination. ${ }^{13}$

Studying the ex vivo Transport of the Optimized EVs and PC-LCNPs Through TM of Rabbits

In this study, the drug amount permeated from the optimized EVs and PC-LCNPs across the rabbit's TM was evaluated over $24 \mathrm{~h}$ in comparison with caroverine solution (Car-Sol). The drug solution was prepared by dissolving caroverine in diluted acetic acid solution $(0.6 \% \mathrm{v} / \mathrm{v})$ to be used as a control. All tests were done in triplicate. Institutional and national guidelines for the care and use of laboratory animals were followed, and the study was approved by Research Ethics Committee, Faculty of Pharmacy, Cairo University, Egypt (PI 1292).

\section{Tympanic Membrane Preparation}

In this test, male albino rabbits weighing approximately 2000 gm were decapitated to facilitate the accessibility to the temporal bone. According to the procedure described by Simons et al, the tissue surrounding temporal bone was separated by scissors to expose the temporal bone, external auditory meatus (EAM), and auditory bulla of both sides. ${ }^{14}$ Each bulla was opened carefully with scissors, and the opening enlarged until the interior-medial surface of the TM could be seen. The extracted tissues including the TM with the surrounding EAM were inspected carefully for any perforations and stored in freezer at $-20^{\circ} \mathrm{C} \pm$ $5{ }^{\circ} \mathrm{C}$ till further use.

\section{Experiment Procedures}

Each TM with the surrounding EAM had attached to the shaft of the USP dissolution apparatus with EAM longitudinal axis parallel to the vessel wall (Figure 1). An accurate volume of the tested formulations equivalent to $3.5 \mathrm{mg}$ caroverine was pipetted into the EAM to cover the lateral surface of the TM (donor). The TM's medial surface was then submerged in the receiving media which consists of $150 \mathrm{~mL}$ normal $(0.9 \%)$ saline and maintained at $37^{\circ} \mathrm{C} \pm 0.5$. The rotation speed of the shaft was $25 \mathrm{rpm}$. One $\mathrm{mL}$ from the receiving compartment was taken after time intervals $(1,2,4,9,21$ and 24 hours) and replaced with an equal volume of fresh medium. The samples were mixed with methanol with ratio 1: 5 and sonicated for 2 minutes $^{15}$ for disruption of the lipid nano carriers, the mixture was then filtered with $0.22 \mu \mathrm{m}$ syringe filter and the drug content was determined using UPLC as previously mentioned. All measurements were performed in triplicate and the mean values \pm SD were calculated. The profile of cumulative amount of the permeated drug per unit area $\left(\mu \mathrm{g} / \mathrm{cm}^{2}\right)$ for each formula was plotted against time (h). The drug flux $\left(\mathrm{J}_{\max }\right)$ at $24 \mathrm{~h}$ and the enhancement ratio (ER) at $24 \mathrm{~h}$ were determined from the following equations: ${ }^{9}$

$$
\begin{gathered}
J_{\max }=\frac{\text { Amount of permeated drug }}{\text { Time } \times \text { Area of the membrane }} \\
E R=\frac{J_{\max } \text { of nano }- \text { formulation }}{J_{\max } \text { of control }}
\end{gathered}
$$

The differences in $\mathrm{J}_{\max }$ values were statistically evaluated by Student's $t$-test. The difference was considered significant at $P \leq 0.05$.

\section{Results and Discussion Determination of the Optimum Concentration of Caroverine for the Preparation of Nano EVs}

Table 3 illustrates the results of drug payload of the prepared elastic vesicular dispersions containing caroverine and their SE after storage for $48 \mathrm{~h}$ at $5^{\circ} \mathrm{C} \pm$ $3^{\circ} \mathrm{C}$. As shown, the drug payload was $\approx 100 \%$ for all tested formulations. Unlike the payload, the SE showed an optimum value at the drug concentration of $0.25 \%$. It was observed that the SE of the vesicular system decreases markedly at higher caroverine concentrations, leading to drug crystallization. This may be due to the hydrophobic nature of caroverine $(\log P=3.5)$. Therefore, caroverine concentration of $0.25 \%$ was chosen for further formulation and evaluation of the nano elastic vesicles (EVs). 


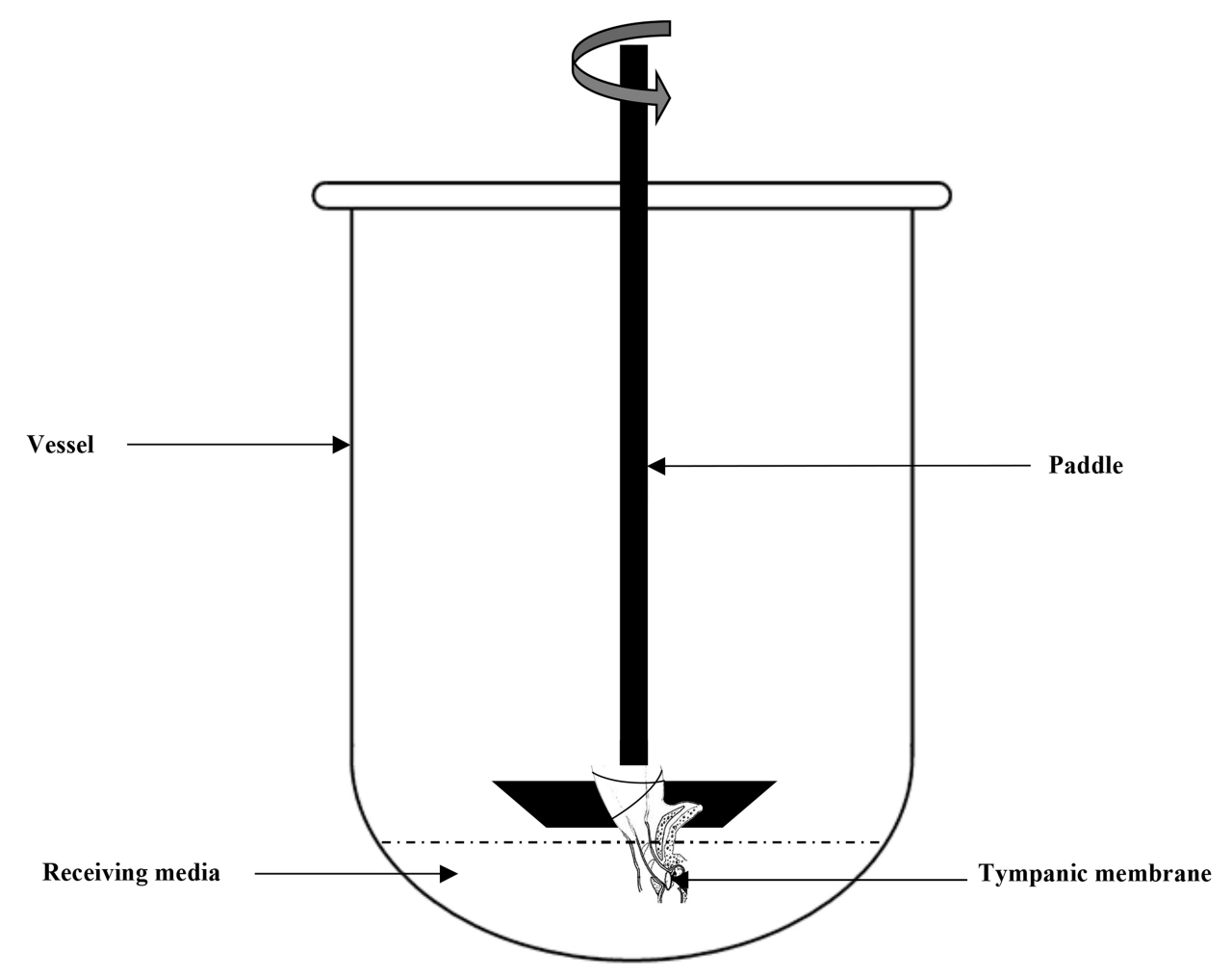

Figure I A schematic diagram represents the ex-vivo permeation test across the rabbit's tympanic membrane using USP dissolution apparatus II.

\section{Characterization of Caroverine-Loaded Nano EVs}

Table 2 demonstrates 17 EVs formulae of different composition. Statistical analysis was done to show the effect of varying the total amount of lipid/surfactant mixture (PC/ T80), concentration of T80 in lipid/surfactant mixture, and the sonication time on the EE\%, PS, ZP, and PDI of the prepared dispersions. All formulae had the same final volume and the same drug concentration. All of the vesicular dispersions had total drug payload $\approx 100 \%$. Statistical analysis of the obtained results revealed that sonication time (factor $\mathrm{C}$ ) does not affect any of the studied responses in a significant manner. Figure 2 shows the effect of the total amount of (PC/ T80) mixture (A), the concentration of T80 (B) and the

Table 3 Payload and Solubilization Efficiency of Elastic Vesicles (EVs) Containing Different Concentrations of Caroverine

\begin{tabular}{|c|c|c|}
\hline $\begin{array}{c}\text { Caroverine Concentration in the EVs } \\
(\% \mathbf{w} / \mathbf{v})\end{array}$ & $\begin{array}{c}\text { Drug Payload } \\
(\%)\end{array}$ & $\begin{array}{c}\text { SE } \\
(\%)\end{array}$ \\
\hline 0.25 & 99.8 & 98 \\
0.5 & 102 & 91 \\
1 & 101 & 48 \\
\hline
\end{tabular}

sonication time $(\mathrm{C})$ on the EE \%, PS, PDI, and ZP of the prepared caroverine EVs formulations.

\section{The Effect of Formulation Variables on the EE\% of Caroverine-Loaded EVs}

As shown in Table 2, the EE\% of the prepared EVs ranged from 64.48 to $89.40 \%$. The ANOVA results showed that the concentration of $\mathrm{T} 80$ had a significant effect on the EE $\%$ of caroverine EVs $(P<0.05)$. It is obvious that the $\mathrm{EE} \%$ increases with increasing concentration of T80 in lipid/ surfactant mixture from $10 \%$ to $20 \%$ and then decreases upon further increase. This may be due to the contribution of the high T80 concentration in the solubilization of the lipid membrane bilayer and formation of some defective and perforated vesicles, along with the possibility of formation of small-sized and rigid mixed micelles during the formulation process. ${ }^{16}$ Besides, the presence of high quantity of the T80 could increase the aqueous solubilization of caroverine, which in turn reduces its entrapment into the vesicular lipid bilayer. ${ }^{17}$ On the other hand, varying the total amount of (PC/T80) mixture or sonication time did not significantly affect the EE\%.

The predicted $\mathrm{R}^{2}$ was calculated by the Design-Expert ${ }^{\mathbb{R}}$ software to measure how the model could predict a response 

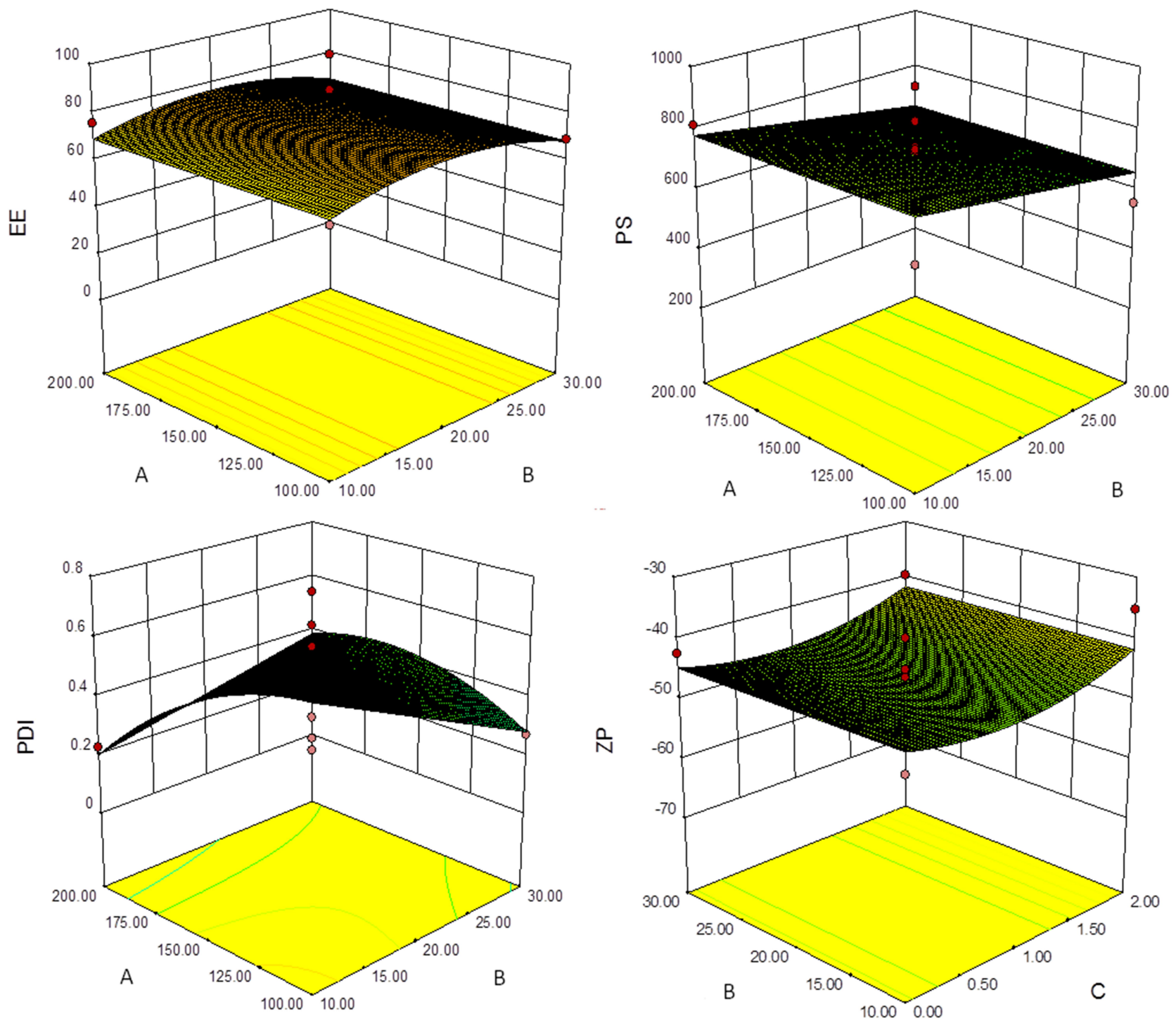

Figure 2 Response surface plot for the effect of $(\mathbf{A})$ total amount of PC/T80 mixture $(\mathrm{mg})$, (B) concentration of T80 in PC/T80 mixture (\%) and (C) sonication time (min) on entrapment efficiency percentage (EE\%), particle size (PS), polydispersity index (PDI), and zeta potential (ZP) of nano elastic vesicles (EVs) formulations.

value by comparing the calculated value with the adjusted $\mathrm{R}^{2}$ value. ${ }^{18}$ Adequate precision was 21.751 and there was a close agreement between the predicted $R^{2}(0.8202)$ and the adjusted $R^{2}(0.8532)$. The generated equation by the software for the $\mathrm{EE}$ analysis was as follows:

$$
\mathrm{EE}=44.84+3.24 \mathrm{~B}-0.082 \mathrm{~B}^{2}
$$

The Effect of Formulation Variables on the PS, PDI, and ZP of Caroverine-Loaded EVs

The PS of the prepared EVs ranged between 541.45 and $984.75 \mathrm{~nm}$ as displayed in Table 2. The ANOVA results showed that the concentration of $\mathrm{T} 80 \mathrm{had}$ a significant effect on the PS of the prepared EVs $(P<0.05)$. It was obvious that upon increasing the concentration of T80, the vesicle mean diameter decreases. This might be the result of low EE\% of caroverine in the vesicles at high T80 concentration. Also, this might be the result of the formation of mixed micelles at high T80 concentration (as previously mentioned in The Effect of Formulation Variables on the EE\% of Caroverine Loaded EVs) showing a very small particle size. ${ }^{19,20}$ However, varying the total amount of (PC/T80) and sonication time did not significantly affect the PS. Adequate precision was 16.259 with a reasonable difference between the predicted $\mathrm{R}^{2}(0.5026)$ and the adjusted $\mathrm{R}^{2}(0.5572)$. The generated equation by the software for the PS analysis was as follows:

$$
\mathrm{PS}=838.29-5.98 \mathrm{~B}
$$


PDI values of the prepared EVs are displayed in Table 2. The values ranged between 0.155 and 0.75 . Statistical analysis revealed that the total amount of PC/T80 mixture had a significant effect on the PDI values of the EVs $(P<0.05)$. Upon increasing the total amount of PC/T80 mixture and T80 concentration, PDI values decrease. Low values of PDI indicate the formation of a homogeneous dispersion with a narrow size distribution. However, concentration of T80 and sonication time had no significant effect on PDI. The generated equation by the software for the PDI analysis was as follows:

$\mathrm{PDI}=0.78-0.045 \mathrm{~B}-4.09 \times 10^{-3} \mathrm{~A}+2.71 \times 10^{-4}$ $\mathrm{BA}-3.7 \times 10^{-5} \mathrm{~B}^{2}$

Finally, the ZP values were between -34.80 and -52.85 $\mathrm{mV}$, as shown in Table 2 . The obtained $\mathrm{ZP}$ values could be considered as a good indicator for assessing the long term physical stability of the prepared dispersion. The stability of colloidal dispersion depends on the charged species present at the particle surface impairing the aggregation and the consequent collapse. Although the model used for the statistical analysis of ZP was significant, the independent variables showed no significant effect on the zeta potential values of caroverine loaded EVs $(P>0.05)$. There is a reasonable difference between the predicted $\mathrm{R}^{2}(0.5387)$ and the adjusted $R^{2}(0.5997)$. The generated equation by the software for the $\mathrm{ZP}$ analysis was as follows:

$$
\mathrm{ZP}=-44.691-5.11 \mathrm{C}+3.318 \mathrm{C}^{2}
$$

\section{Formulation Optimization and Validation of EVs}

Desirability function was employed using Design-Expert ${ }^{\circledR}$ software for the prediction of the optimized EVs formulation. ${ }^{21}$ The numerical optimization process was carried out based on the outlined constraints of each of the set responses, Table 1. The most desirable formulation, which composed of $150 \mathrm{mg}$ of PC/T80 mixture containing 30\%
T80, was selected and prepared as the optimized formulation (OPT-EVs). For assessing the validity of the optimization procedures, the optimized formulation was prepared and the responses were measured and compared to that of the predicted values. ${ }^{22}$ As illustrated in Table 4, there is a close agreement between the results. Therefore, OPT-EVs formulation was selected and exposed for further studies.

\section{Characterization and Evaluation of Caroverine-Loaded PC-LCNPs}

Stable, non-lamellar, PC-LCNPs were formed by self assembly of PC/GMO in aqueous solution in the presence of stabilizers. The resulting average particle size (z-average) of prepared dispersions was $188.8 \pm 1.27 \mathrm{~nm}$ and PDI was 0.37 \pm 0.07 . The dispersion had negative zeta potential of $-22.5 \pm$ $0.64 \mathrm{mV}$. The examined formulation showed a good physical appearance with no agglomeration or aggregation even after storage. The dispersed PC-LCNPs were stabilized by using a combination of non ionic surfactants (T80 and PF-127) that provided a steric stabilizing effect by their residence at the surface of LC particles ${ }^{23}$ and the ability of reducing the surface free energy. ${ }^{24}$ In addition, the PC-LCNPs formulation displayed a good texture properties due to the unique bio adhesive nature of GMO. ${ }^{25}$ From the clinical point of view, this bioadhesive property is proposed to enhance the settling of the formulation into the patient's ear canal, which in turn could maximize the exposure of therapeutic agent to the TM and promote its diffusion into the middle and/or inner ear. ${ }^{14}$

The incorporation of $\mathrm{PC}$ into the ternary mixture of $(\mathrm{PC} /$ $\mathrm{GMO} /$ water) formed a very interesting new biocompatible system. This system exhibited a good physical and chemical properties as it enabled the accommodation of high drug load into a thermodynamically stable structure. These characteristics depended mainly on the intercalation of PC into the liquid crystalline molecules of the GMO that tuned the

Table 4 The Predicted and the Observed Responses of the Optimized Elastic Vesicular Formulation (OPT-EVs)

\begin{tabular}{|c|c|c|c|c|c|c|c|c|}
\hline \multirow[t]{2}{*}{ Formula } & \multicolumn{5}{|l|}{ Factors } & \multicolumn{3}{|c|}{ Responses } \\
\hline & $\begin{array}{l}\text { Concentration of } \mathrm{T} 80 \text { in }(\mathrm{PC} / \\
\mathrm{T} 80) \text { mixture (\%) }\end{array}$ & $\begin{array}{l}\text { Total amount of }(\mathrm{PC} / \mathrm{T} 80) \\
\text { mixture }(\mathrm{mg})\end{array}$ & $\begin{array}{l}\text { Sonication } \\
\text { time } \\
(\mathrm{min})\end{array}$ & & $\begin{array}{l}Y_{1}: \\
E E \\
(\%)\end{array}$ & $\begin{array}{l}Y_{2}: \\
P S \\
(n m)\end{array}$ & $\begin{array}{l}Y_{3}: \\
\text { PDI }\end{array}$ & $\begin{array}{l}Y_{4}: \mathbf{Z P} \\
(\mathrm{mV})\end{array}$ \\
\hline OPT-EVs & 30 & 150 & 2 & $\begin{array}{l}\text { Observed } \\
\text { values } \\
\text { Predicted } \\
\text { values }\end{array}$ & $\begin{array}{l}72 \\
68\end{array}$ & $\begin{array}{l}580 \\
608.4\end{array}$ & $\begin{array}{l}0.3 \\
0.32\end{array}$ & $\begin{array}{l}-39 \\
-41.64\end{array}$ \\
\hline
\end{tabular}

Abbreviation: OPT-EVs, optimized formulation of caroverine-loaded elastic vesicles. 
Table 5 Stability Results of the Fresh and Stored Samples of OPT-EVs and PC-LCNPs in Refrigerator $\left(5 \pm 3^{\circ} \mathrm{C}\right)$ and Cabinet $\left(30{ }^{\circ} \mathrm{C} /\right.$ $65 \% \mathrm{RH})$

\begin{tabular}{|c|c|c|c|c|c|c|}
\hline Formula & Condition & $\begin{array}{c}\text { Drug Payload } \\
\text { (\%) }\end{array}$ & $\begin{array}{l}\text { EE } \\
(\%)\end{array}$ & $\begin{array}{c}\text { PS } \\
(\mathbf{n m})\end{array}$ & PDI & $\begin{array}{l}\text { ZP } \\
(\mathrm{mV})\end{array}$ \\
\hline OPT-EVs & $\begin{array}{c}\text { Fresh } \\
\text { Cabinet } \\
\left(30^{\circ} \mathrm{C} / 65 \% \mathrm{RH}\right) \\
\text { Refrigerator } \\
\left(5 \pm 3^{\circ} \mathrm{C}\right)\end{array}$ & $\begin{array}{l}102 \\
96 \\
98\end{array}$ & $\begin{array}{l}68 \pm 1.4 \\
68 \pm 1.6 \\
65 \pm 1\end{array}$ & $\begin{array}{l}580 \pm 4.9 \\
650 \pm 5.5 \\
670 \pm 7.0\end{array}$ & $\begin{array}{l}0.3 \pm 0.01 \\
0.4 \pm 0.05 \\
0.33 \pm 0.04\end{array}$ & $\begin{array}{l}-39 \pm 0.50 \\
-40 \pm 0.30 \\
-42 \pm 0.25\end{array}$ \\
\hline PC-LCNPs & $\begin{array}{c}\text { Fresh } \\
\text { Cabinet } \\
\left(30^{\circ} \mathrm{C} / 65 \% \mathrm{RH}\right) \\
\text { Refrigerator } \\
\left(5 \pm 3^{\circ} \mathrm{C}\right)\end{array}$ & $\begin{array}{c}103 \\
91.60 \\
96.60\end{array}$ & & $\begin{array}{l}188 \pm 1.27 \\
180 \pm 5.30 \\
190 \pm 1.20\end{array}$ & $\begin{array}{l}0.37 \pm 0.01 \\
0.40 \pm 0.05 \\
0.39 \pm 0.01\end{array}$ & $\begin{array}{l}-22.50 \pm 0.64 \\
-24.50 \pm 0.24 \\
-25.50 \pm 0.28\end{array}$ \\
\hline
\end{tabular}

Abbreviations: OPT-EVs, optimized formulation of caroverine loaded nano vesicles; PC-LCNPs, phosphatidylcholine based liquid crystalline nanoparticles.

curvature of the nanostructure and enlarged the size of the aqueous channels/pore size containing drug and increased the drug payload ( $1 \%$ versus $0.25 \%$ in case of EVs).

\section{Comparative Stability Study}

Table 5 illustrates the results of the stability study of PCLCNPs and OPT-EVs after 3 months of storage at the predetermined conditions. It is worth mentioning that both formulae had maintained their good physical appearance during the storage period and no obvious aggregation or agglomeration was observed. Regarding the OPT-EVs, the results showed a significant increase in the vesicles diameter $(P<0.05)$ at different storage conditions. This might be due to the fusion and aggregation of vesicular lipid bilayer after storage.

With respect to PC-LCNPs, the statistical analysis revealed a non-significant difference $(P>0.05)$ in the PS, PDI and ZP between the fresh and stored samples. It may return to the steric stabilization effect of PF-127, a triblock co-polymer of ethylene oxide and propylene oxide (PEO-PPO-PEO), and T80 as a surfactant. Hence, it was concluded that the liquid crystalline nanoparticles of $(\mathrm{PC} /$ GMO) comprised a thermodynamically stable system as it maintained its physical and chemical stability under the normal and stress (accelerated) condition.

\section{Morphology of Caroverine-Loaded Nano-Carriers Using Transmission Electron Microscopy}

The TEM micrograph displayed the morphology of the prepared OPT-EVs and PC-LCNPs. Regarding the OPT-
EVs, Figure 3 revealed unilamellar, spherical-shaped nano-vesicle with a well identified core shell structure. On the other hand, the micrograph of PC-LCNPs is displayed in Figure 4. It shows polyangular-shaped nanoparticles of relatively small size. The PS displayed in the micrographs was within the nano range and in alignment with the Zetasizer measurements.

\section{Ex vivo Transport Study}

Caroverine permeation profiles from different formulations across rabbit's TM are illustrated in Figure 5. The Figure

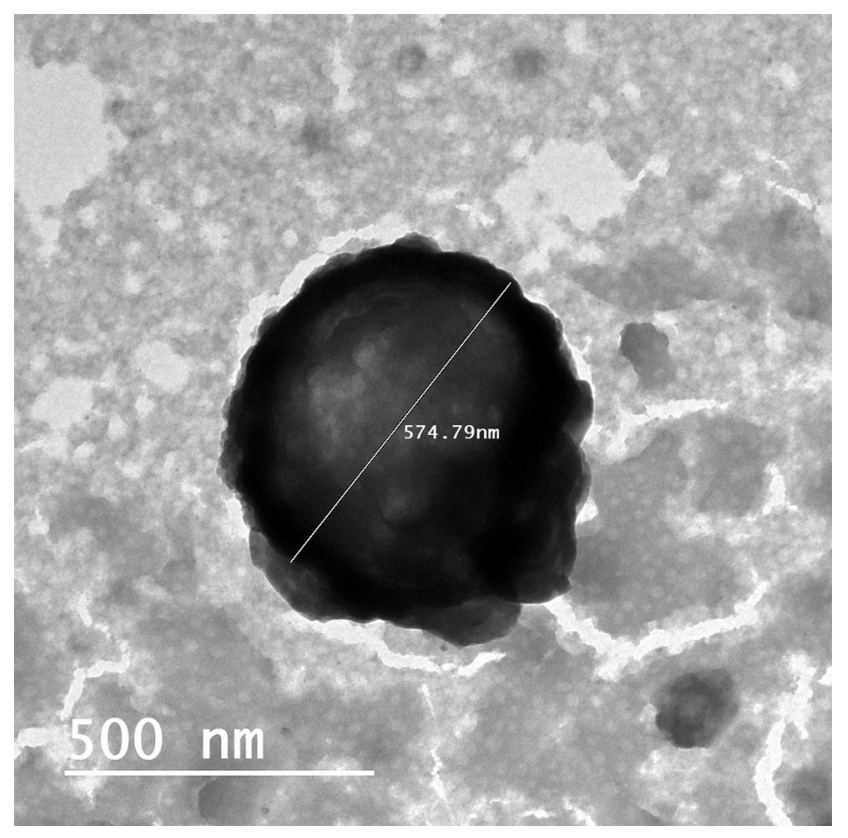

Figure 3 Transmission electron micrographs of the optimized nano elastic vesicles (OPT-EVs) at magnification of $100,000 \times$. 


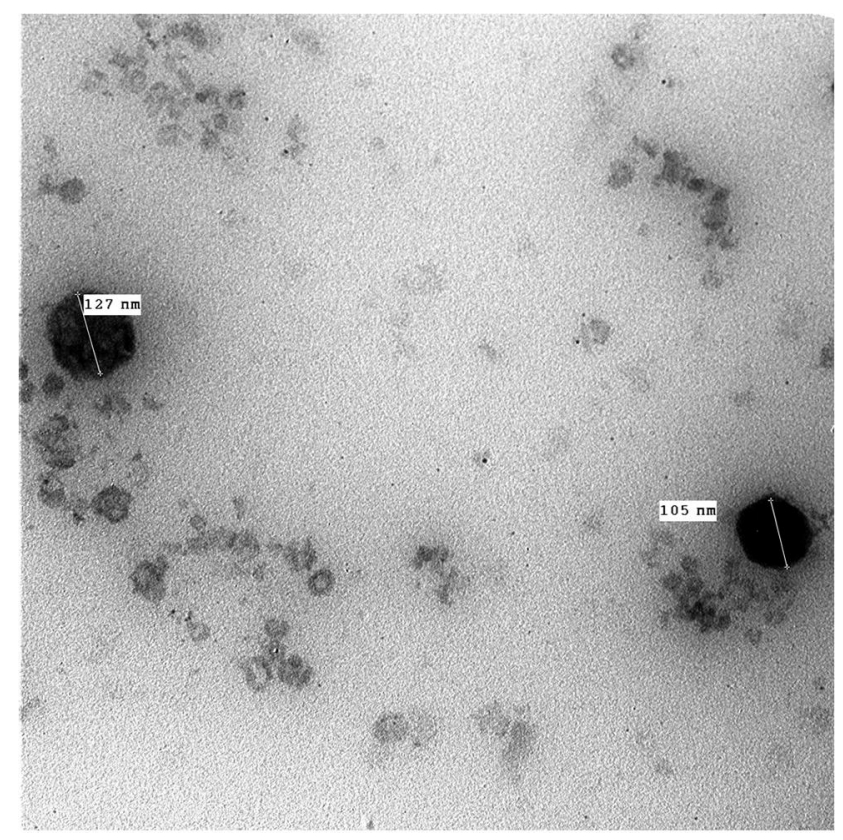

Figure 4 Transmission electron micrographs of the phosphatidylcholine based liquid crystalline nanoparticles (PC-LCNPs) at magnification of $100,000 \times$.

displayed the cumulative amounts of caroverine permeated from OPT-EVs and PC-LCNPs over $24 \mathrm{~h}$ compared to the drug solution. The results revealed a significant increase in the cumulative drug flux values of the PC-LCNPs $(699.58 \pm$ $\left.100 \mu \mathrm{g} / \mathrm{cm}^{2}\right)$ compared to the OPT-EVs $\left(250 \pm 45 \mu \mathrm{g} / \mathrm{cm}^{2}\right)$ at $P<0.05$. Moreover, the calculated ER values demonstrated two-fold increase in the drug permeation efficiency of the PC-LCNPs across the TM in contrast to the OPT-EVs which showed a marked decline in the drug permeation efficiency across the same biological membrane. This might be attributed to the attractive characteristics of the liquid crystalline

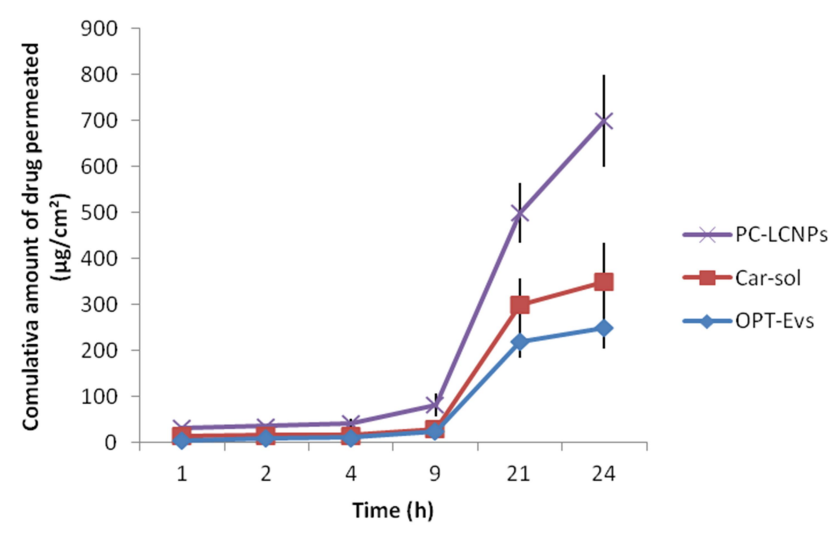

Figure 5 Drug permeation profile through rabbit's tympanic membrane (TM) of the optimized nano elastic vesicles formulation (OPT-EVs) and phosphatidylcholine based liquid crystalline nanoparticles (PC-LCNPs), in comparison with the caroverine solution (Car-sol). nano carriers which revealed small nano-sized particles compared to that of the elastic nano vesicular system along with the high penetration efficiency of the contained T80 and PF127. Further, tailoring the lipid membrane of the LCNPs by the PC molecules increased the nanoparticles elasticity and enhanced drug penetration efficiency through the stratum corneum which is considered the main barrier to the dermal and trans-tympanic drug delivery. ${ }^{26}$

\section{Conclusion}

Several advantages have been observed upon incorporating the PC into various nano-systems. PC based LCNPs is a new attractive candidate for the inner ear drug delivery application. Implementation of this new system displayed a significantly higher membrane surface area which allowed drug superloading using simple and applicable manufacturing process as compared to the elastic nano vesicles. Moreover, it provides high penetration efficiency and good physical and chemical stability. Briefly, the obtained results suggest that the formulated PC-LCNPs (containing 5\% GMO, 0.5\% PC, 35\% PG, 5\% ethanol, 0.3\% T80, 0.6\% PF-127, 0.3\% ascorbic acid, 0.6\% acetic acid, and 55\% distilled water (w/v)) can be used as potential nano-sized carriers for enhancing the non invasive oto-topical delivery of caroverine, providing a means for the treatment of tinnitus.

\section{Disclosure}

The authors report no conflicts of interest for this work.

\section{References}

1. Melcher JR, Levine RA, Bergevin C, Norris B. The auditory midbrain of people with tinnitus: abnormal sound-evoked activity revisited. Hear Res. 2009;257(1-2):63-74. doi:10.1016/j.heares.2009.08.005

2. Ehrenberger K. Topical administration of caroverine in somatic tinnitus treatment: proof-of-concept study. Int Tinnitus J. 2005;11 (1):34-37.

3. Altschuler RA, Sheridan CE, Horn JW, Wenthold RJ. Immunocytochemical localization of glutamate immunoreactivity in the guinea pig cochlea. Hear Res. 1989;42(2):167-173. doi:10.1016/ 0378-5955(89)90142-1

4. Oestreicher E, Arnold W, Ehrenberger K, Felix D. New approaches for inner ear therapy with glutamate antagonists. Acta Otolaryngol. 1999;119(2):174-178. doi:10.1080/00016489950181611

5. Liu H, Hao J, Li KS. Current strategies for drug delivery to the inner ear. Acta Pharm Sin B. 2013;3(2):86-96. doi:10.1016/j.apsb.2013. 02.003

6. Swan EEL, Mescher MJ, Sewell WF, Tao SL, Borenstein JT. Inner ear drug delivery for auditory applications. Adv Drug Deliv Rev. 2008;60 (15):1583-1599. doi:10.1016/j.addr.2008.08.001

7. McCall AA, Swan EEL, Borenstein JT, Sewell WF, Kujawa SG, McKenna MJ. Drug delivery for treatment of inner ear disease: current state of knowledge. Ear Hear. 2010;31(2):156. doi:10.1097/ AUD.0b013e3181c351f2 
8. Zou J, Sood R, Zhang Y, Kinnunen PK, Pyykkö I. Pathway and morphological transformation of liposome nanocarriers after release from a novel sustained inner-ear delivery system. Nanomedicine. 2014;9(14):2143-2155. doi:10.2217/nnm.13.181

9. Al-mahallawi AM, Khowessah OM, Shoukri RA. Nanotransfersomal ciprofloxacin loaded vesicles for non-invasive trans-tympanic ototopical delivery: in-vitro optimization, ex-vivo permeation studies, and in-vivo assessment. Int J Pharm. 2014;472 (1-2):304-314. doi:10.1016/j.ijpharm.2014.06.041

10. Ahmad A, Alkharfy KM, Wani TA, Raish M. Application of BoxBehnken design for ultrasonic-assisted extraction of polysaccharides from Paeonia emodi. Int J Biol Macromol. 2015;72:990-997. doi:10.1016/j.ijbiomac.2014.10.011

11. Aziz DE, Abdelbary AA, Elassasy AI. Fabrication of novel elastosomes for boosting the transdermal delivery of diacerein: statistical optimization, ex-vivo permeation, in-vivo skin deposition and pharmacokinetic assessment compared to oral formulation. Drug Deliv. 2018;25(1):815-826. doi:10.1080/10717544.2018.1451572

12. Rizwan S, Assmus D, Boehnke A, et al. Preparation of phytantriol cubosomes by solvent precursor dilution for the delivery of protein vaccines. Eur J Pharm Biopharm. 2011;79(1):15-22. doi:10.1016/j. ejpb.2010.12.034

13. Shamma RN, Elsayed I. Transfersomal lyophilized gel of buspirone $\mathrm{HCl}$ : formulation, evaluation and statistical optimization. J Liposome Res. 2013;23(3):244-254. doi:10.3109/08982104.2013.801489

14. Simons EJ, Hoare TR, Kohane DS, Langer RS Tympanic membrane permeating ear drops and uses thereof. Google Patents; 2009.

15. Vinod K, Anbazhagan S, Kumar MS, Sandhya S, Banji D, Rani AP. Developing ultra deformable vesicular transportation of a bioactive alkaloid in pursuit of vitiligo therapy. Asian Pac J Trop Dis. 2012;2 (4):301-306. doi:10.1016/S2222-1808(12)60066-8

16. Almgren M. Mixed micelles and other structures in the solubilization of bilayer lipid membranes by surfactants. Biochim Biophys Acta Biomembr. 2000;1508(1):146-163. doi:10.1016/S0005-2736(00) 00309-6

17. Srivastava R, Nagappa A. Application of surface activity in therapeutics. Stud Interface Sci. 2005;21:233-293.
18. Annadurai G, Ling LY, Lee J-F. Statistical optimization of medium components and growth conditions by response surface methodology to enhance phenol degradation by Pseudomonas putida. J Hazard Mater. 2008;151(1):171-178. doi:10.1016/j.jhazmat.2007.05.061

19. van den Bergh BA, Wertz PW, Junginger HE, Bouwstra JA. Elasticity of vesicles assessed by electron spin resonance, electron microscopy and extrusion measurements. Int J Pharm. 2001;217(1-2):13-24. doi:10.1016/S0378-5173(01)00576-2

20. Basha M, Abd El-Alim SH, Shamma RN, Awad GEA. Design and optimization of surfactant-based nanovesicles for ocular delivery of Clotrimazole. J Liposome Res. 2013;23(3):203-210. doi:10.3109/ 08982104.2013 .788025

21. Basalious EB, Shawky N, Badr-Eldin SM. SNEDDS containing bioenhancers for improvement of dissolution and oral absorption of lacidipine. I: development and optimization. Int J Pharm. 2010;391 (1-2):203-211.

22. Hao J, Fang X, Zhou Y, et al. Development and optimization of solid lipid nanoparticle formulation for ophthalmic delivery of chloramphenicol using a Box-Behnken design. Int $J$ Nanomedicine. $2011 ; 6: 683$.

23. Kojarunchitt T, Hook S, Rizwan S, Rades T, Baldursdottir S. Development and characterisation of modified poloxamer 407 thermoresponsive depot systems containing cubosomes. Int J Pharm. 2011;408(1-2):20-26. doi:10.1016/j.ijpharm.2011.01.037

24. Wadsater M, Barauskas J, Nylander T, Tiberg F. Formation of highly structured cubic micellar lipid nanoparticles of soy phosphatidylcholine and glycerol dioleate and their degradation by triacylglycerol lipase. ACS Appl Mater Interfaces. 2014;6(10):7063-7069. doi:10.1021/am501489e

25. Nielsen LS, Schubert L, Hansen J. Bioadhesive drug delivery systems: I. Characterisation of mucoadhesive properties of systems based on glyceryl mono-oleate and glyceryl monolinoleate. Eur J Pharm Sci. 1998;6(3):231-239.

26. Libster D, Aserin A, Wachtel E, Shoham G, Garti N. An HII liquid crystal-based delivery system for cyclosporin A: physical characterization. J Colloid Interface Sci. 2007;308(2):514-524. doi:10.1016/j.jcis.2006.12.084
International Journal of Nanomedicine

\section{Publish your work in this journal}

The International Journal of Nanomedicine is an international, peerreviewed journal focusing on the application of nanotechnology in diagnostics, therapeutics, and drug delivery systems throughout the biomedical field. This journal is indexed on PubMed Central, MedLine, CAS, SciSearch ${ }^{\mathbb{R}}$, Current Contents ${ }^{\mathbb{B}} /$ Clinical Medicine,
Journal Citation Reports/Science Edition, EMBase, Scopus and the Elsevier Bibliographic databases. The manuscript management system is completely online and includes a very quick and fair peer-review system, which is all easy to use. Visit http://www.dovepress.com/ testimonials.php to read real quotes from published authors. 